\title{
Ambiente Rural e Natureza: diferenças que produzem especificidades de uma escola
}

Marcelo Giraldi de Castro ${ }^{1}$

Antonio Carlos Rodrigues de Amorim ${ }^{2}$

\section{RESUMO}

\section{AMBIENTE RURAL E NATUREZA: DIFERENÇAS QUE PRODUZEM ESPECIFICIDADES DE UMA ESCOLA.}

Este artigo é um fragmento de pesquisa de Mestrado em Educação cujo objetivo foi lançar/ produzir olhares para um conjunto de práticas de representação que produzem especificidades e diferenças à escola rural. Estivemos em busca de uma diversidade de sentidos específicos que, ao ser movimentada, procurou apresentar múltiplas possibilidades de representação que circulam na confluência de uma escola rural em Piracicaba (SP), configurando esta pesquisa como um estudo de caso. Consideramos que a prática de representação de qualquer coisa que seja nunca nos coloca à frente de apenas uma possibilidade de significação, pois ao atribuirmos um sentido estamos recorrendo aos significados que nos vão sendo disponibilizados através da cultura, que, por sua vez, são dependentes de outros tantos significados, e por isso, estão sempre deslizando e mudando conforme as circunstâncias histórias e o contexto cultural vivido. Esse posicionamento nos permitiu olhar para esta escola como sendo atravessada por sentidos e significados associados, por exemplo, às temáticas ambientais, aglutinando especificidades que em determinadas condições passam a constituí-la como diferente.

Palavras-chave: ambiente; estudos culturais; escola.

1 Possui graduação em Engenharia Agronômica pela Universidade de São Paulo, Especialização em Educação Ambiental pela Universidade de São Paulo, Licenciatura em Ciências Agrárias pela Universidade de São Paulo e Mestrado em Educação pela Universidade Estadual de Campinas. Ministrou aulas de Educação Ambiental, Metodologia do Ensino de Ciências Físicas e Biológicas e Biologia Aplicada à Educação para turmas de graduação em Pedagogia na Universidade Estadual Santa Cruz em Ilhéus (BA). Tem experiência nas áreas de Agronomia e Educação. É professor da Fundação Bradesco em Aparecida de Goiânia - Goiás.

2 Professor Associado (MS-5) da Universidade Estadual de Campinas, no Departamento de Educação, Conhecimento, Linguagem e Arte, pesquisador no Laboratório de Estudos Audiovisuais (OLHO), pesquisador associado no Laboratório de Estudos Avançados em Jornalismo (LABJOR) e pesquisador associado do Gabinete de Filosofia da Universidade do Porto, Portugal. Possui experiência de investigação na área de Educação, com ênfase nas relações entre Currículo e Culturas nos espaços escolares e não escolares. Nas pesquisas, busca articulações principalmente entre os seguintes temas: educação, arte e cultura visual; currículo, imagens e pós-estruturalismo. 


\section{ABSTRACT \\ RURAL ENVIRONMENT AND NATURE: DIFFERENT WAYS WICH PRODUCE A SPECIFIC SCHOOL.}

This article is a fragment of Master Education dissertation, which aimed to produce different ways to look towards a set of (representation practices) practices of representation. That produces particularities and differences for a rural school. We searched for a diversity of specific senses and when it was moved up it aimed to present multiple possibilities of representation that go around the perimeter of a Piracicaba's rural school. We considered that whatever the practice of representation is, it never puts us before at only one possibility of signification, for when a sense is given it is supported by other meanings available through culture, which or dependent on many other meanings, and that is why they are always moving and changing according to historical circumstances and the cultural moment. By this view it allowed us to look at this school as being a place influenced by senses and meanings (associated to) related, for example, to environmental themes, gathering up particularities that in some conditions turn it to be different.

Key words: environment; cultural studies; school.

\section{APROXIMAÇÕES}

Este artigo associa-se a uma pesquisa de mestrado, na qual estendemos olhares para uma escola rural na cidade de Piracicaba, localizada no estado de São Paulo, em busca de suas representações e percebendo como as práticas de significação apresentam efeitos que produzem as especificidades e diferenças dessa escola. Para tanto nos foi muito importante a aproximação com referenciais teóricos que articulam educação e cultura, em especial o campo dos "Estudos Culturais da Educação" (WORTMANN, 2001 e 2002) e MARTINO (2012).

Ao atribuirmos sentidos, estamos recorrendo aos significados que dispomos através da cultura e tais significados são dependentes de outros, deslizando e mudando conforme a circunstância e o contexto cultural. Assim, compreendido o conceito de representação, optar por trabalhar tendo ele como um dos referenciais nos permitiu visualizar e supor a existência não de uma especificidade caracterizadora da escola rural, mas, sim, de várias especificidades que se apresentam e se traduzem em múltiplas possibilidades de compreensão e caracterização. 
Pudemos olhar para essa escola rural como um espaço que se mostra atravessado de sentidos e aglutinado por especificidades e isso nos impeliu na busca de compreensões sobre aspectos pouco visíveis e em movimento nesse espaço, que, em determinadas circunstâncias, parecem querer produzi-lo como diferenciado. Dizendo de outra forma, desejamos lançar/produzir olhares para aquilo que essa escola rural quis construir em particular como algo diferente.

Tratando essa pesquisa como um estudo de caso, pudemos assumir olhar para os movimentos que nela se delineiam como circunscritos a determinadas condições. Assumimos, metodologicamente, que são os efeitos desses movimentos, em um caso específico, que nos interessam apresentar em narrativas, descrições e ensaios de análises neste texto. Uma escola rural pertencente à Secretaria Municipal de Educação de Piracicaba é o lugar por meio do qual aconteceram as incursões investigativas. A compreensão dessa escola como lugar não a restringe a seu espaço físico, material, aos alunos e às pessoas que nela trabalham, mas, também, a algumas outras instâncias e sujeitos que produzem sentidos sobre e para ela, entre eles as famílias dos alunos, a Secretaria Municipal de Educação com seus profissionais e documentos ${ }^{3}$, os jornais impressos de diferentes épocas, fotografias, etc. Desta forma, pretendemos dilatar, descentrar e permeabilizar as fronteiras físicas do espaço dessa escola, capturando, em um contexto um pouco mais ampliado, as produções de seus sentidos e significações.

Destacadamente, porém, a realização de um conjunto de entrevistas foi um dos principais instrumentos de movimentação das representações, que resultou na escolha de temáticas e direções das descrições e análises que serão apresentadas neste artigo. Foram entrevistadas vinte e uma pessoas, envolvidas de diferentes formas com a escola em questão: seis mães, três pais, duas exalunas, seis professoras, a diretora, uma supervisora de ensino, o secretário municipal de educação e dois funcionários (uma assistente social e uma engenheira agrônoma) de um projeto ${ }^{4}$ com atuação em todas as escolas municipais rurais de Piracicaba, incluindo nossa escola em questão.

As entrevistas se orientaram através de dois temas estabelecidos previamente e que foram conduzindo e sendo conduzidos à medida que os entrevistados produziam suas considerações. Esses temas giravam em torno de questões a respeito da escola e do espaço rural. Além disso, foram sendo

3 Decidimos olhar para alguns textos produzidos pela escola e para a escola rural e que apresentam e discutem aspectos diretamente relacionados à questão da sua especificidade e que, portanto, participam também da circulação de significados no espaço dessa escola rural. São eles: Lei 9394 de 20/12/96 (Lei de Diretrizes e Bases da Educação Nacional), Resolução no 01 de 3/04/2002 (Diretrizes Operacionais para Educação Básica nas Escolas do Campo), Diretrizes da I Conferência Municipal de Educação de Piracicaba e Projeto Político-Pedagógico da Escola.

4 Trata-se do Projeto "Núcleo Rural de Atendimento à Criança e ao Adolescente".

Ci. Huma. e Soc. em Rev. RJ, EDUR, vol. 35, n. 2, jul / dez, p. 126-145, 2013 
desencadeadas durante a realização das entrevistas, rememorações sobre histórias e experiências vividas que nos apresentaram muitas representações interessantes sobre os entrevistados e seus lugares de vida.

O fato de também já termos participado desse projeto direcionado às escolas rurais da rede de ensino municipal - que incluía, também, a escola escolhida como foco de nosso estudo - facilitou o processo de contato com as diferentes pessoas entrevistadas e nos fez assumir, na relação de entrevistas com os participantes da pesquisa, as marcas como sujeitos atuantes desse projeto e, portanto, produtores de sentidos e participantes de rede de relações de poder.

As entrevistas foram, então, dimensionadas como trocas de experiências e observadas nas suas posições privilegiadas e que, durante a conversa, traziam à tona algumas relações entre rural, urbano e natural; passado e futuro; vivências e conhecimento.

Com esse dimensionamento das entrevistas, em que apostamos? Que pelos sentidos que as entrevistas apresentam, pudemos criar uma escrita em vários momentos com aspectos de narrativa, pontuando multiplicidades da escola rural, em especial argumentando como a diferença (rural) que identifica a escola participa de uma série de processos de significação, ou seja, constitui representações. Na esteira dessa questão, não iremos apenas demonstrar sua relevância e contradições, mas principalmente apresentar sua constituição como lugar perpassado por intensas relações de conflitos e de tomadas de posição privilegiadas, campo de força no qual o que representa o rural é uma iniciativa à sua persistência ou à sua revitalização.

\section{OLHARES QUE EMERGEM PELA EXPERIÊNCIA: A PRODUÇÃO DE ESPECIFI- CIDADES}

Em 1999, acompanhando o início do processo de municipalização do ensino fundamental de Piracicaba, foi criado o "Projeto Núcleo Rural de Atendimento à Criança e ao Adolescente" (PNR) ${ }^{5}$, no qual se teve oportunidade de trabalhar até o ano de 2001.

Desenvolvido pela Secretaria Municipal de Educação (SME) em parceria com a Pastoral do Serviço da Caridade ${ }^{6}$ (PASCA) e o apoio de outras secretarias municipais, entidades e órgãos envolvidos direta ou indiretamente com questões relacionadas ao meio rural, o PNR, através de

5 O PNR ainda continuava em atividade naquele ano de 2004.

6 A PASCA, entidade sem fins lucrativos, foi criada em 25 de janeiro de 1988 com o intuito de aglutinar todos os trabalhos desenvolvidos pela Pastoral Social da Diocese de Piracicaba e de responder juridicamente por eles, considerando cada trabalho como Unidade Prestadora de Serviço (UPS). 
uma equipe multidisciplinar composta de assistentes sociais e engenheiros agrônomos, atuava em escolas municipais de Piracicaba consideradas rurais. $\mathrm{O}$ alcance de suas ações não estava restrito exclusivamente ao espaço escolar, abrangendo, também, as famílias dos alunos.

Pretendemos apresentar, a seguir, leituras que busquem algumas práticas que, através das ações do PNR, tentavam produzir marcas de especificidades para essas escolas rurais.

Partimos, então, dos pontos referenciais que norteavam o planejamento e a execução de todas as ações do PNR: o desenvolvimento rural e o resgate e a valorização de sua cultura.

O presente Projeto, inserido no contexto de um Programa mais amplo de fixação rural, visa o atendimento a uma faixa etária específica tendo como lócus privilegiado as escolas rurais.

Espaço central de socialização para as crianças e adolescentes das comunidades alvo das atividades propostas, a escola rural permite perseguir os objetivos de resgate dos aspectos culturais, e de gestão de alternativas à monocultura da cana-de-açúcar a partir de um currículo alternativo que atende às peculiaridades e necessidades do homem do campo $(\mathrm{s} / \mathrm{p})^{7}$

Essa interação com as escolas proposta pelo PNR aconteceu, principalmente, através do apoio assistencial e técnico às famílias e da realização de atividades práticas de ensino desenvolvidas com os alunos e previamente programadas com as professoras.

Esse último aspecto, relevante para nossa discussão, tinha como objetivo:

A melhoria das condições da escola e do ensino, a diminuição da repetência e da evasão, desenvolvendo um currículo alternativo que atenda às peculiaridades da criança da zona $\operatorname{rural}(\mathrm{s} / \mathrm{p})^{8}$

Desta forma, frases do tipo "desenvolvimento rural", "resgate cultural", "ensino diferenciado", "fixação da população", "peculiaridades da criança da zona rural”, "problemáticas familiares específicas", entre outras, marcavam e construíam um conjunto de categorizações e especificidades, cujos significados passavam a circular e a se aglutinar a outros significados carregados pelas pessoas envolvidas naquele trabalho, estabelecendo, assim, diferentes entendimentos e posicionamentos. Neste contexto, as diferenças para a escola rural eram discursivamente produzidas.

7Extraído do texto: Projeto Núcleo Rural de Atendimento à Criança e ao Adolescente. Piracicaba. Secretaria Municipal de Educação (mimeo, s/d).

8 Idem. 
O PNR passava a estabelecer um campo bastante produtivo de práticas de representação e de disputa de significações sobre o rural e seus elementos caracterizadores, como a família, o trabalho, a cultura, a escola, etc.

É deste último ponto - a escola rural - que passaremos a focalizar o relato sobre o PNR, direcionando-o para momentos que fizeram emergir reflexões importantes para aquilo que foi produzido com a pesquisa de mestrado e que poderá nos aproximar de um campo de visão no qual seja possível perceber, também, os efeitos produtivos de nossas representações, que vão sendo constituídas por outros significados adquiridos circunstancialmente dentro do contexto cultural vivido.

Destacaremos, a seguir, alguns momentos dessa experiência do PNR, direcionando buscas pelas marcas expressas em ações e acontecimentos que, entre outras coisas, queriam produzir especificidades para as escolas rurais envolvidas com o projeto.

\section{INCORPORAÇÃO E CORPORIFICAÇÃO DO DISCURSO AMBIENTAL}

À medida que as atividades de práticas educativas foram realizadas mediante a programação estabelecida pelo PNR, um outro conjunto de interesses começava a tomar corpo em reuniões específicas com os membros da equipe do projeto e nos HTPC's com as diretoras e professoras das escolas rurais.

Esse conjunto de interesses que passaram a entrar em circulação era movimentado pelos discursos da Educação Ambiental, cuja temática central - a questão ambiental - passa a se instaurar, nas últimas três décadas, como discussão de extrema relevância para todos os segmentos e instituições sociais, surgindo como proposta de reflexão sobre o atual modelo de desenvolvimento e sobre as relações da humanidade com o planeta e da sociedade com a natureza.

Dentro da equipe do PNR, a Educação Ambiental entrou, principalmente, a partir da identificação e engajamento pessoal de alguns de seus membros com as suas propostas. Dos três agrônomos do projeto, dois deles mostravam um forte interesse em viabilizar, inicialmente, a sua discussão e, posteriormente, a sua prática no interior das escolas.

Nossas identificações e concepções em relação ao assunto giravam em torno da possibilidade de mediar, continuamente nas escolas, uma discussão que pudesse questionar de maneira circunstanciada o modelo de sociedade vigente e a sua sustentabilidade a médio e a longo prazos. 
Para isso, as ações e práticas educacionais do PNR deveriam ser pensadas no sentido de contribuir para a produção de novas sensibilidades em relação à questão ambiental nos contextos rurais em que estávamos trabalhando, seja através das escolas, seja através das famílias.

Para nós, o processo de sensibilização se daria em ambientes abertos que facilitassem um contato estético com a natureza.

Segundo Crespo (2000), privilegiando as pedagogias "experienciais" ou "vivenciais", essa tendência, praticada sobretudo por organizações não-governamentais ambientalistas e comunitárias, desenvolve estratégias diferenciadas segundo perspectivas, por exemplo, mais próximas àquelas desenvolvidas pela educação popular-comunitária, inspirada na pedagogia de Paulo Freire e discípulos.

O terceiro agrônomo que compunha a equipe não compartilhava das mesmas concepções, mostrando-se bastante refratário a qualquer discussão sobre o assunto. Seu posicionamento estava fortemente vinculado à manutenção da proposta de trabalho anterior que concebeu o PNR, na qual a ênfase estava apoiada quase que exclusivamente na prática de ensino de técnicas produtivas através de hortas escolares.

Isso gerou uma disputa de argumentações e entendimentos sobre os rumos que os trabalhos do projeto deveriam tomar, o que acabou isolando esse último posicionamento dentro da equipe, rompendo com as vias de diálogo que, com o passar do tempo, foram sendo esgotadas.

O PNR entrava em um momento peculiar, pois a partir desse embate, dois posicionamentos e duas propostas de trabalho passaram a coexistir.

Nessa disputa pelo poder da representação de diferentes visões do rural e por aquilo que deveria ser inserido no currículo das escolas através do PNR, os tensionamentos gerados chegaram a vias de fato com a demissão desse membro da equipe ao final do segundo ano de funcionamento do projeto.

Prevaleciam, então, os argumentos relacionados à incorporação da Educação Ambiental, que gradativamente foi sendo aglutinada às ações do projeto.

Também reforçava esses argumentos o fato de que a Educação Ambiental já estava circulando nas escolas através dos discursos e materiais oficiais da política de educação, tanto federal como municipal. 
Em alguns HTPC's (Horário de Trabalho Pedagógico Coletivo) que contavam com a participação da supervisão escolar e em cursos oferecidos pela própria Secretaria Municipal de Educação, veiculavam-se as propostas da Educação Ambiental como algo a ser incorporado e multiplicado no cotidiano de trabalho de todas as escolas da rede, independente de serem rurais, urbanas ou da periferia.

Certamente, os Parâmetros Curriculares Nacionais (BRASIL, 1997) foram um dos principais veículos de introdução desse discurso nas escolas. , eram os Parâmetros Curriculares Nacionais (BRASIL, 1997).

Nesta convergência entre esses dois poderosos discursos, ambientalista e político-educacional, pôde-se visualizar as argumentações necessárias para a agregação da Educação Ambiental ao planejamento de atividades do PNR e ao currículo das escolas rurais. A premissa era o resgate dos vínculos individuais, coletivos e culturais com o espaço e com a realidade vivida pelos alunos dessas escolas poder ser potencializado através de atividades de sensibilização e de (re)conhecimento do ambiente local e das suas conexões com o ambiente global.

$\mathrm{Na}$ mesma esteira de argumentos, estava a percepção sobre os processos de transformação do rural e as novas funções que vinha adquirindo, pois além das tradicionais atividades produtivas relacionadas ao setor agropecuário, outras tantas atividades rurais não-agrícolas ligadas à produção de bens e serviços passaram a ocupar espaços significativos dentro desse rural, o que José Graziano da Silva e colaboradores (2002), em seus estudos e pesquisas empíricas, convencionaram chamar de "o novo rural brasileiro".

Entre as novas atividades do meio rural, estão aquelas associadas às demandas ambientais e ao (re)encontro com a natureza, como por exemplo, o ecoturismo, o turismo rural, a preservação de reservas e recursos naturais e a própria Educação Ambiental.

Desta forma, essa percepção de uma dinâmica de convívio entre um espaço rural cada vez mais tecnificado e industrializado e um outro que, ao se aproximar da natureza, procura resgatar um convívio humano cada vez mais harmônico e equilibrado, nos fez acreditar ainda mais nas potencialidades que a Educação Ambiental poderia oferecer se agregada às ações do PNR nas escolas rurais. 
Esses princípios que afirmavam as potencialidades da Educação Ambiental dentro do projeto selecionaram aspectos do meio rural para serem apresentados e integrados aos currículos escolares que teriam dificuldades de estabelecer relações com a seguinte fala de uma mãe nesta pesquisa. Por essa fala, encontramos aspectos da vida no meio rural que os discursos da Educação Ambiental deixariam de fora ao realizarem aproximações do rural com a natureza.

A partir do segundo ano de funcionamento do projeto, a Educação Ambiental começou, então, a ser movimentada em algumas das escolas através das discussões e dos textos que levávamos aos HTPC's e, também, pelas atividades de sensibilização e estudo do meio que realizávamos com os alunos.

Essa nova movimentação, associada aos resultados e repercussões obtidas no primeiro ano de trabalho, despertou o interesse de outras escolas da rede municipal que sondaram a Secretaria de Educação sobre a possibilidade de suas inclusões ao PNR.

Apesar de estarem localizadas em bairros urbanos geralmente periféricos, assumimos, experimentalmente, o trabalho em quatro dessas escolas.

Essa possibilidade de abertura relacionava-se à inserção da Educação Ambiental às ações do PNR e ao maior aprofundamento de nossas reflexões sobre os processos de transformação do rural piracicabano, o que acabou produzindo uma visão mais maleável e abrangente tanto em relação ao nosso trabalho quanto em relação ao público que atendíamos e que não era exclusivamente oriundo da zona rural.

A visão dicotomizada que no início do trabalho nos fazia enxergar o rural como lugar de especificidades e distinções em relação ao urbano, passava a ser deslocada, então, por uma visão de um continuum espacial, ou seja, de interação e interpenetração entre rural e urbano.

Essas novas representações e formas de olhar para nossos lugares de trabalho traziam-nos ainda mais sentidos para a Educação Ambiental, pois nela caberiam tanto o rural quanto o urbano e o periférico.

Entretanto, ao final desse segundo ano, foi avaliado pela coordenação do PNR que os trabalhos realizados nas escolas urbanas poderiam descaracterizar por demais os objetivos gerais do projeto e, principalmente, o seu caráter de especificidade no atendimento à população rural. Desta forma, eles não mais deveriam ter continuidade para o ano seguinte. 
Mas, apesar disso, uma, das quatro escolas em que esses trabalhos experimentais foram realizados, acabou sendo incorporada definitivamente ao PNR. Isso pôde ser "permitido" porque, pela sua localização geográfica, ela poderia ser considerada como rural, já que estava fora dos limites (apesar de muito próxima a ele) que estabeleciam o perímetro urbano do município.
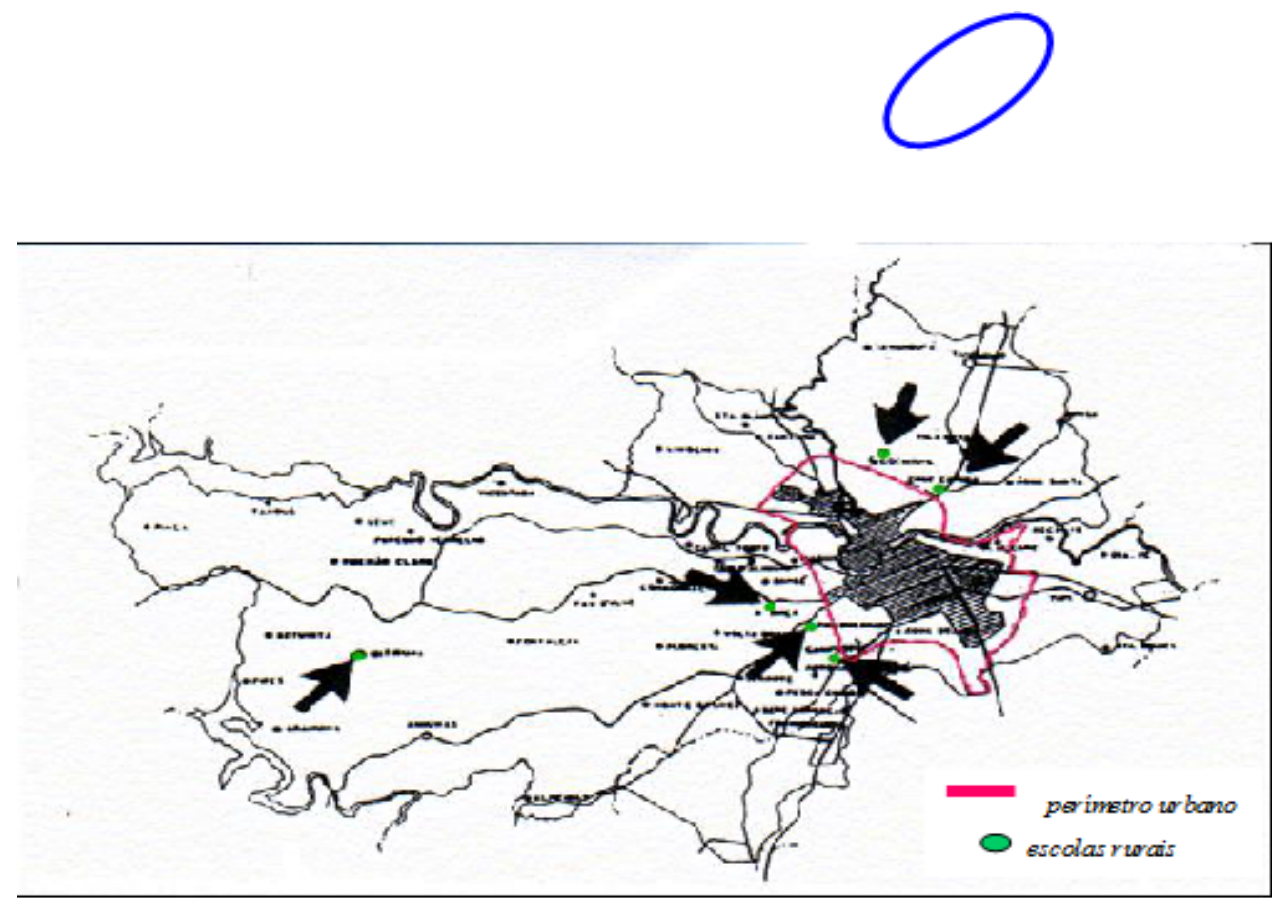

O mapa indica a localização de cinco escolas rurais inicialmente atendidas pelo PNR e a Sexta (circunscrita em azul) posteriormente.

O discurso pela manutenção das "especificidades rurais" do PNR reposicionava, então, um deslocamento que estava sendo iniciado por um outro discurso, o da Educação Ambiental.

Desta forma, o projeto recuperava sua característica inicial de trabalho através das escolas rurais, independentemente de suas peculiaridades locais e do perfil do público atendido.

Mas esse reposicionamento não significou um apagamento, pois os dois discursos permaneceram no interior do PNR produzindo sinergias que movimentaram novas possibilidades de ação. Reorganizava-se, então, um outro conjunto de significados e representações que pareciam buscar a construção de uma possível relação de identificação entre o rural e o ambiental. 
Em uma reunião de avaliação e planejamento da equipe do PNR, no início do terceiro ano de nosso trabalho, foram levantadas algumas propostas que tinham o objetivo de criar meios para a discussão de assuntos que continuávamos a achar relevantes tanto para as escolas rurais onde atuávamos quanto para a continuidade de nossos trabalhos.

Em nossa percepção da época, havia um considerável desconhecimento por parte das educadoras (professoras e diretoras) no que dizia respeito a alguns aspectos das relações socioculturais e socioambientais presentes no meio rural.

\begin{abstract}
Apesar do trabalho realizado junto aos alunos desde o início das atividades, do projeto ter sido produtivo em vários aspectos, a equipe de técnicos do Projeto Núcleo Rural avaliou, ao final do ano 2000, que seria de fundamental importância uma mudança de estratégia no sentido da implementação de ações mais efetivas e consistentes em torno da capacitação das professoras e diretoras das escolas rurais, pois a grande maioria dessas educadoras vivee tem origem nazonaurbanae de uma formageral desconhecem a complexidadee o potencial educativo existente nas questões ambientais, culturais e sociais do espaço $\operatorname{rural}(\mathrm{s} / \mathrm{p})^{9}$
\end{abstract}

Entendíamos que o distanciamento cultural, pelo fato da origem urbana ${ }^{10}$ da grande maioria das professoras e diretoras das escolas rurais, poderia ser uma das principais dificuldades para a compreensão sobre a importância e a necessidade de uma reflexão mais aprofundada e, até mesmo, mais interessada sobre tais aspectos.

Trabalhamos, então, com a proposta de pensar a construção de um formato em que fosse possível viabilizar um espaço para essas possíveis discussões e, mais do que isso, um espaço onde, também, fosse possível vivenciá-las.

Nesse mesmo ano, coincidentemente, estaria finalizando um curso de especialização em Educação Ambiental ${ }^{11}$, cuja motivação para a participação tinha total relação com as nossas identificações e buscas profissionais dentro dos trabalhos do projeto. Uma oportunidade, então, se apresentava, pois entre as atividades finais de avaliação do curso, a principal seria a elaboração e execução de um projeto de intervenção educacional.

\footnotetext{
9 Extraído do projeto de intervenção educacional produzido por Marcelo Giraldi de Castro para o curso de especialização em Educação Ambiental (mimeo)

10 Há de se deixar claro que essa também era a condição de todos os técnicos que atuavam no PNR.

11 Curso "Formação de Educadores para Sociedades Sustentáveis" realizado no período de agosto de 2000 a setembro de 2001 pelo Laboratório de Estudos e Políticas Ambientais da ESALQ/USP.
} 
Juntando essa tarefa a ser cumprida aos indicativos da reunião de avaliação e ao planejamento do PNR, foi esboçada uma proposta de um curso para as educadoras das escolas rurais cuja atividade central seria a realização de um estudo do meio.

“O reconhecimento dos espaços ambientais no sentido mais amplo, isto é, considerando não só aspectos ecológicos, mas, também, sociais, econômicos e culturais, é de fundamental importância para que as pessoas possam transformar suas atitudes e ampliar suas percepções em relação a estes locais onde vivem ou atuam profissionalmente.

A zona rural, ambiente altamente transformado pelas ações bumanas, apresenta inúmeras especificidades que podem ser trabalhadas de diversas formas dentro de um processo pedagógico.

Uma destas formas é o estudo do meio. Estudar o meio é ler sensitivamente o que o espaço nos diz. É estudar os diversos conjuntos significativos da natureza e da sociedade, objetivando conscientizar o educando sobre o cotidiano que o envolve e do qual tem que participar.

Pode ser utilizado como recurso de aprofundamento dos conteúdos escolares e de questionamento da realidade, promovendo uma maior integração de alunos e professores com estes locais" ${ }^{12}$ por meio das atividades de Educação Ambiental que já estavam sendo implementadas pelos técnicos nas escolas, construíram-se argumentos que acabaram sendo convincentes e suficientes para se justificar a importância da realização do curso.

A ideia, apresentada à Secretaria Municipal de Educação, foi bem recebida e aprovada quando, a partir daí, debruçamo-nos juntamente com a equipe do projeto para a construção do projeto final do curso, seu planejamento e organização.

$\mathrm{Na}$ verdade, a concepção de um curso centralizado em uma atividade amplamente utilizada em propostas educativas de Educação Ambiental surge como desdobramento das leituras dos textos, das aulas, das atividades e das trocas de experiência que circularam ao longo de um outro curso e que passaram a circular, também, nas reuniões da equipe do PNR, possibilitando o desdobramento da proposta do campo da ideia para o campo da ação.

Realizou-se,então, duranteos mesesdeabril, maioejunhode2001,ocursointitulado "Estudodo meio rural: uma abordagem pedagógica”, com carga horária de 31 horas dividida em 10 encontros semanais.

12 Texto introdutório do guia de campo que orientavam as observações e atividades do estudo do meio extraído de meu Projeto de Intervenção Educacional produzido para o curso de especialização "Formação de Educadores Ambientais para Sociedades Sustentáveis" (mimeo, 2001). 
Procuramos trabalhar nesses encontros do curso, atividades, temas e assuntos que pudessem dar suporte a uma reflexão mais aprofundada sobre aquilo que seria vivenciado na atividade central do curso - o Estudo do Meio Rural -, procurando mostrar, também, suas possíveis potencialidades como prática pedagógica a ser desenvolvida com os alunos.

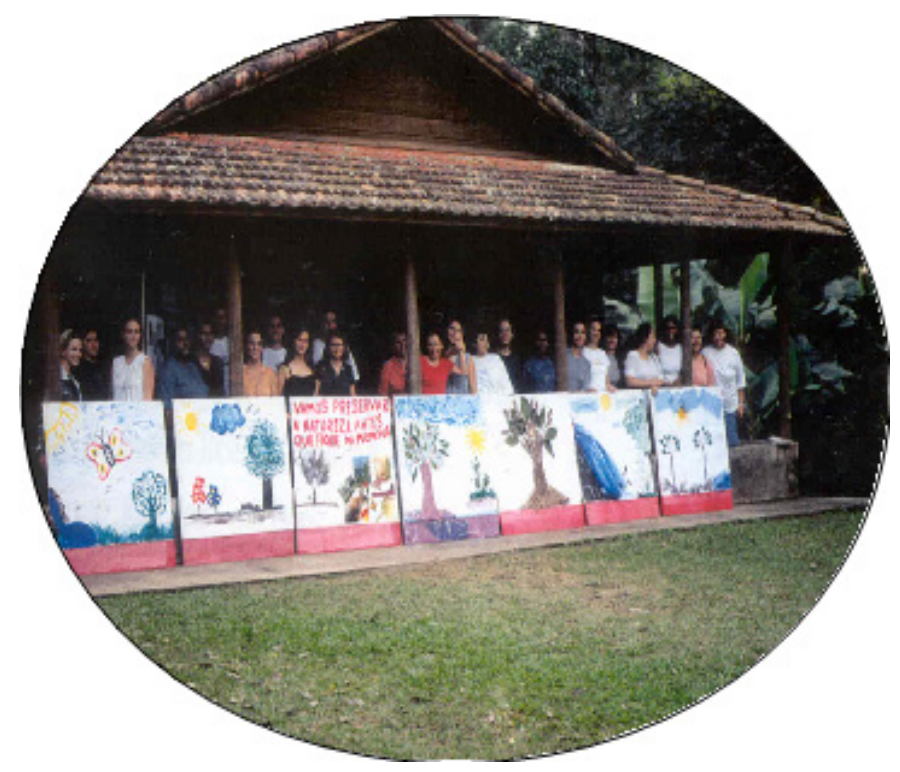

Além disso, projetávamos que alguns desdobramentos do curso poderiam, no final, subsidiar futuras discussões e propostas de implementação de um currículo diferenciado nas escolas rurais, um dos objetivos do PNR, expresso, também, na redação do objetivo geral do projeto do curso.

Contribuir para a capacitação das professoras das escolas rurais de Piracicaba, lançando subsídios e gerando reflexões que possam estimular e orientar a construção de propostas pedagógicas e adequações curriculares contemplando as especificidades caracterizadoras do espaço rural (p.10) ${ }^{13}$

É interessante destacar que, por se tratar de um curso com emissão de um certificado pela Secretaria Municipal de Educação, a divulgação teve de ser aberta para toda a rede de ensino, redimensionando a nossa proposta de realização de um curso direcionado especificamente para as educadoras das escolas rurais.

13 Extraído de Projeto de Intervenção Educacional produzido para o Curso de Especialização "Formação de Educadores Ambientais para Sociedades Sustentáveis" (mimeo, 2001). 
O texto abaixo apresenta as justificativas que foram construídas para isso:

(...) o tema que permeia essas diferentes especificidades é o meio ambiente: assim, para melhorar a qualidade de ensino das escolas rurais, estimulou-se a adequação do currículo à realidade vivenciada pelo aluno, através de intervenções pedagógicas feitas pelos Engenheiros Agrônomos.

Este trabalho contribuiu para a mudança de postura dos alunos em relação ao ambiente, porém, essas mudanças serão potencializadas se o educador, que permanece com a criança por 25 horas semanais, incorporar valores de respeito ao ambiente na sua prática cotidiana.

Para tanto, é essencial o re-direcionamento do trabalho para sensibilizar a equipe escolar sobre a importância dos problemas ambientais (...) ${ }^{14}$

Essa abertura acabou, surpreendentemente, superando nossa expectativa de participação. De uma previsão inicial de cerca de 35 participantes, o número chegou a 58, sendo 26 educadoras de escolas rurais e 32 de escolas urbanas.

Diante dessa contingência, o discurso da Educação Ambiental apresentou-se, neste contexto, e reiterando outros movimentos já apresentados neste texto, como uma possibilidade de abarcar e apagar aquilo que era ou poderia ser visto como diferente ou específico, aglutinando-se como marca que fazia estabelecer, circunstancialmente, algumas identificações entre o rural e o ambiental/natural. Esse foi o efeito na rede de significações da escola rural que o curso gerou.

Independentemente das escolas em que trabalhavam, sejam rurais, periféricas ou urbanas, as professoras produziram, então, expectativas de um curso que estava fortemente marcado pelas propostas da Educação Ambiental, a partir de uma pergunta incluída na ficha de inscrição: "O que

você espera do curso?”. Para as professoras, as expectativas apresentadas não chamavam atenção para relações com o rural, indicando uma compreensão da Educação Ambiental fora da relação com as questões que marcariam a especificidade da escola, seja rural, seja urbana.

14 Extraído do "Projeto de Solicitação de Subvenção para Desenvolvimento do Projeto Núcleo Rural de Atendimento à Criança e ao Adolescente”. Piracicaba. Pastoral do Serviço da Caridade (mimeo, dezembro de 2000). 
As relações de identificação entre rural e ambiental/natural, efetuadas quando se assume a Educação Ambiental como um forte discurso que marcaria a especificidade da escola rural, estão presentes em várias discussões que acontecem em outros campos sociais, além da educação, podendo indicar que participam de redes de significação que se entrecruzam com as que nesta pesquisa de caso foram sendo produzidas.

Para Braida e Froehlich (2000), a associação entre o rural e o natural parece ser, à primeira vista, uma constatação até certo ponto bastante compreensível, principalmente quando se dá a partir de uma relação comparativa com um espaço urbano artificializado, "na medida em que o rural é pensado como o âmbito em que o humano lida com a natureza para satisfazer as suas necessidades sob a forma de uma agri-cultura". Desta forma, o rural passa, então, a ser "pensado como o lugar em que a cultura intervém na natureza" ou, ainda, "como lugar natural do natural" (p.1).

Apesar de aparentemente compreensível, essa identificação é, na verdade, bastante problemática, pois, segundo os autores, envolve diferentes conceitos e representações sobre a natureza, incluindo algumas possíveis incompatibilidades.

Atualmente, existe uma gama de preocupações particulares com esta 'natureza'. A ecologia e a deterioração ambiental, as representações sobre o território nacional e do papel contemporâneo da agricultura no desenvolvimento e a procura de equacionamentos para as crises sociais especialmente associadas ao emprego e às transformações da agricultura, recolocam a problemática da 'ruralidade' e da 'natureza' no contexto das sociedades contemporâneas. Especula-se sobre um 'renascimento do rural', da necessidade de 'padrões de vida mais naturais', da elaboração de supostas teorias do 'desenvolvimento sustentável' e do 'desenvolvimento local' e de novas relações entre a cidade e o campo (p.2)

Algumas análises sobre o rural atual constatam a convivência, nesses espaços, de duas vertentes: uma industrialista, da máxima artificialização da natureza e da agricultura e outra recuperadora de uma busca pelo rural enquanto ambiente de vida natural, benéfico e equilibrado.

Nessa última vertente, estão incorporadas as novas percepções sobre a relação entre espaços urbanos e rurais e as novas concepções sobre modos de habitar e estilos de vida.

A sociedade fundada na aceleração do ritmo da industrialização passa a ser questionada pela degradação das condições de vida nos grandes centros. O contato com os espaços mais naturalizados é, então, valorizado, "o ar puro, a simplicidade da vida, e a natureza são vistos como elementos 'purificadores' do corpo e do espírito poluídos pela sociedade industrial” (CARNEIRO, 1997, p.153). 
Os consequentes atributos atuais ligados à modernidade urbana, como a poluição, violência, desemprego, favelização, etc., passam a reconsiderá-la, pois conformam "condições de vida deterioradas e um modo de habitar degradado, desvalorizado, rejeitado, associado à pobreza, à exclusão e à delinqüência: uma representação negativa, em suma”. Essas formas de diferenciação, características de nosso mundo contemporâneo, podem conduzir à afirmação de "especificidades múltiplas e diversificadas dos territórios, sejam urbanos ou rurais, desvalorizando-se antigas oposições e antagonismos" (BRAIDA e FROEHLICH, 2000, p.17).

Para Canário (2000), os espaços rurais representam "em si mesmos, um recurso fundamental, na medida em que se constituem como reserva de espaço físico”, principalmente no sentido da proteção e reprodução da natureza e da paisagem. Além disso, apresentam “um conjunto de valores culturais e ambientais que lhe são intrínsecos, mas relativamente 'invisíveis' no quadro de uma lógica de mercado". Para o autor, a existência desses espaços está evidenciada no âmbito das teorias de economia ambiental que recorrem ao conceito de um "valor de existência" assentado nos princípios da diversidade ecológica, cujos valores estão relacionados a "critérios de raridade, especificidade e funcionalidade" que não exigem um em termos de sistemas "reconhecimento de um valor de mercado de curto prazo" (p. 126).

Geralmente, propostas de valorização e desenvolvimento rural assentam-se na produção de especificidades locais e reivindicações a diferenças culturais; da mesma forma, reivindicações ecológicas e ambientais também atuam na produção de especificidades para os espaços rurais servindo como linguagem potencial para uma reconsideração sociopolítica do rural e

(...) é em nome de concepções e avaliações tecnocientíficas que se desenvolvem, hoje, conflitos e lutas em relação aos impactos das infra-estruturas dos modelos agrícolas, das poluições ou dos projetos de utilização dos recursos naturais. A questão do ambiente - no espaço rural - confrontaria, assim, não somente usos diferentes (agrícolas, naturalistas, turísticos, etc.), mas também categorias de especialização científicas e técnicas capazes de fornecer representações de base para uma gestão do espaço (Mormont apud BRAIDA e FROEHLICH, 2000, p.19)

Portanto, as novas aproximações com a "natureza" que, nas sociedades contemporâneas, vêm a se implementar, trazem novas interpretações e leituras sobre os espaços rurais, onde quer que se localizem. Para Froehlich e Rodrigues (1998), essas interpretações teóricas levam sempre em consideração a presença da esfera política, "pois assumem que o complexo político das relações de força redefine hoje as dimensões do espaço-tempo em diferentes realidades, conformando as condições de possibilidades singulares de cada espaço social” para, diante dessa visão, para compreender o espaço rural contemporâneo. 


\section{PELA FRONTEIRA ENTRE RURAL E URBANO, É POSSÍVEL A ESPECIFICIDADE?}

Os movimentos de produção de especificidades da escola rural no município de Piracicaba, tanto pelo Projeto Núcleo Rural quanto no Projeto Político Pedagógico da Escola neste estudo de caso, além das experiências trazidas pelas entrevistas, inclusive por rememorações, marcam as diferenças entre rural e urbano.

Estabelecem uma problemática importante para esta pesquisa que diz respeito às possibilidades de áreas de contato entre esses dois universos culturais e o que as representações podem produzir neste contexto.

Pareceu-nos instigante trabalhar com a ideia de fronteira para explorar outros aspectos que as entrevistas apresentam e estender a busca por compreender por que é produtiva a persistência em fixar especificidades da escola rural e quais são seus efeitos em termos culturais.

Fergunson e Gupta (2000) consideram as fronteiras comolugares de “contradições incomensuráveis” e sugerem que ao invés de descartá-las, deveríamos considerá-las como "uma conceituação mais adequada do local 'normal' do sujeito pós-moderno” (p. 45).

Poderíamos, desta forma, visualizá-la não apenas como um limite topográfico/geográfico fixo entre dois outros espaços, mas também, como um espaço de intensa movimentação, um entrelugar de encontro, de disputa e de aglutinação de significados, um entrelugar de produção de sentidos, um entrelugar de expressões representadas.

Para o estudo de caso pesquisado, as considerações de Friedeman (2002) sobre as fronteiras fixarem e demarcarem, mas serem, em si mesmas, linhas imaginárias, fluidas e em permanente processo de mutação, expressam-se nas falas de diferentes pessoas que trabalharam mais proximamente à implantação da proposta de um projeto político pedagógico específico para a escola rural e estão permeadas de dilemas e de controvérsias. Por exemplo, para Paulo ${ }^{15}$ a necessidade de demarcação da fronteira entre rural e urbano é fundamental para que se confira significados de existência às pessoas que moram no meio rural, pois "há uma diferença muito grande entre o homem do meio rural e o homem do meio urbano. E o homem rural dificilmente se integra... quer dizer, as referências dele estão no campo, estão na natureza, na família. Então, esses laços e essa referência na área urbana são quebrados, não há uma preparação para essa passagem e aí isso faz com que as pessoas, apesar de viverem na zona urbana, nunca consigam se integrar".

15 Nome fictício do Secretário de Educação do Município de Piracicaba na época da realização da pesquisa. 
Por sinal, uma igualdade de condições e a necessidade de diferenciação estão em constante relação disputando lugares nas redes de significação para o projeto da escola rural; e quando se trata de uma especificidade de ligação com a terra, forte indicativo nas palavras de Paulo, que marca diferenças entre as pessoas que vivem no meio rural em relação àquelas que vivem no meio urbano, a fala de Cássia ${ }^{16}$ se mostra desestabilizadora: “(...) se a gente pegar essas crianças que vêm das periferias para estudar nas escolas rurais... como acontece no Godinhos ${ }^{17}$ hoje, por exemplo, que nós estamos recebendo as crianças dos Bosques dos Lenheiros ${ }^{18}$ porque a escola lá não dá mais conta do número de crianças... se você for fazer um diagnóstico daquelas famílias, a maioria tem uma ligação com terra, ou elas vieram do Nordeste, ou elas também vieram da própria zona rural de Piracicaba. (...) esse resgate, mesmo com as crianças da área urbana, é importante, sabe. Então, isso não é uma coisa que dificulta tanto porque Piracicaba é uma cidade que tem uma cultura rural muito forte. É uma cidade construída em cima da cultura rural. Então, eu acho que isso não deve ser um complicador nessas escolas".

Sendo assim, o questionamento que agora nos orienta e no qual escolhemos para sintetizar alguns dos movimentos que são possíveis a partir da ideia de fronteira é o seguinte: será que épossível o rural sem o urbano? Para tanto, apresentamos uma produtividade do contato entre esses dois universos que representam as funções desta escola rural que foi o estudo de caso desta investigação.

O contato ou a afirmação de que ele deve ser evitado é produtivo na instituição de diferenças entre o rural e a periferia do urbano.

Pierucci (2000) fala de uma "produtividade social da diferença”, ou seja, que a diferença, no campo das relações de representação, faz emergir "outras diferenças além dela, por causa dela, contra ela mesma", desencadeando-se "um processo que é ao mesmo tempo discursivo e material de afirmação de outras diferenças culturais já compartilhadas por indeterminado número de indivíduos, mas que eram, até então, socialmente invisíveis em seu valor (real ou imaginário) e inconcebíveis em sua legitimidade (social ou política) (p.120)”.

A legitimidade que a escola deste estudo de caso acaba conferindo, sócio e politicamente à diferença periferia é muito problemática, principalmente quando se trata de uma discriminação em movimento de inclusão de especificidades e particularidades para a escola rural.

16 Nome fictício de uma supervisora de ensino do município de Piracicaba.

17 Escola da zona rural.

18 Escola da periferia urbana. 


\section{REFERÊNCIAS}

BRAIDA, C. R. e FROEHLICH, J. M. Aporias do discurso pós-moderno sobre a natureza e o rural. Trabalho apresentado no XXXVIII Congresso Brasileiro de Economia e Sociologia Rural, 2000. Disponível em http://www.ufsm.br/desenvolvimentorural/06.pdf

CANÁRIO, R. $A$ Escola no Mundo Rural: Contributos para a construção de um objecto de estudo. Porugal. Revista Educação Sociedade \& Culturas, nº 14, 121-139, 2000.

CARNEIRO, M. J. Ruralidade: novas identidades em construção. In: Anais XXV,Congresso da SOBER.Natal: SOBER. pp.147-185, 1997.

CARVALHO, I.C.M. Desafios e Dilemas políticos das lutas e movimentos ambientais. In: QUINTAS, J.S. (org.) Pensando e praticando a educação ambiental na gestão do meio ambiente. Instituto Brasileiro do Meio Ambiente e dos Recursos Ambientais, Brasília: Ed. IBAMA, 2000.

CASTRO, M.G. Entre especificidades e diferenças: olhares para representações de uma escola rural no município de Piracicaba, SP. Campinas: Faculdade de Educação, 2004 (Dissertação de Mestrado).

CRESPO, S. Educar para a Sustentabilidade: A Educação Ambiental no programa da Agenda 21. In: BARCELOS, V.H.L.; NOAL, F.O.; REIGOTA, M. Tendências da Educação Ambiental Brasileira. Santa Cruz do Sul. EDUNISC, 2000.

FERGUSON, J. e GUPTA A. Mais além da “cultura”: espaço, identidade e política da diferença. In: ARANTES, A.A.(org.) O Espaço da Diferença. Campinas: Papirus, 2000.

FRIEDMAN, S.S. O “falar da fronteira”, o hibridismo e a performatividade. Eurozine, 2002. Disponível em http://www.eurozine.com.

FROEHLICH, J.M; RODRIGUES, I.S. O Turismo Rural e as transformações no espaço agrário. Recife. XXI Congresso Brasileiro de Ciências da Comunicação. INTERCOM, 1998. Disponível em: www. intercom.org.br/papers/xxi-ci/gt19 
GRAZIANO DA SILVA, J; CAMPANHOLA, C; DEL GROSSI, M. O que há de realmente novo no rural brasileiro. Cadernos de Ciência \& Tecnologia, Brasília, v.19, n.1, p.37-67, jan/abr, 2002).

MARTINO, Mauro Sá. A área dos estudos culturais: consenso genealógico e indefinição epistemológica. Comunicação \& Sociedade. Ano 33, n. 57, p. 79-101. jan./jun. 2012.

PIERUCCI, A.F. Ciladas da Diferença. São Paulo: Editora 34, 2000.

WORTMANN, M.L.C. Análises culturais: um modo de lidar com histórias que interessam a educação. In: COSTA, M.V (org.) Caminhos investigativos II: outros modos de pensar e fazer pesquisa em educação. Rio de Janeiro: DP\&A, 2002.

WORTMANN, M.L.C. O uso do termo representação na Educação em Ciências e nos Estudos Culturais. Pro-Posições, vol. 12, nº 1(34), p.151-161, março de 2001.

DOCUMENTO BRASIL. Parâmetros Curriculares Nacionais: Meio Ambiente. Brasília. Secretaria de Educação Fundamental - MEC/SEF, 1997. 